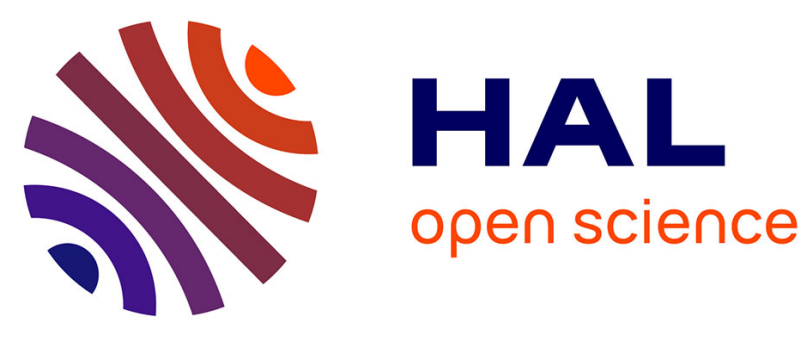

\title{
Effects of chronic exercise on the endocannabinoid system in Wistar rats with high-fat diet-induced obesity.
}

Francois-Xavier Gamelin, Julien Aucouturier, Fabio Arturo Iannotti, Fabiana

Piscitelli, Enrico Mazzarella, Teresa Aveta, Melissa Leriche, Erwan Dupont, Caroline Cieniewski-Bernard, Valerie Montel, et al.

\section{To cite this version:}

Francois-Xavier Gamelin, Julien Aucouturier, Fabio Arturo Iannotti, Fabiana Piscitelli, Enrico Mazzarella, et al.. Effects of chronic exercise on the endocannabinoid system in Wistar rats with high-fat diet-induced obesity.. Journal of Physiology and Biochemistry, 2016, Journal of Physiology and Biochemistry, 72, pp.183-199. 10.1007/s13105-016-0469-5 . hal-02534651v2

\section{HAL Id: hal-02534651 \\ https://hal.univ-lille.fr/hal-02534651v2}

Submitted on 25 May 2021

HAL is a multi-disciplinary open access archive for the deposit and dissemination of scientific research documents, whether they are published or not. The documents may come from teaching and research institutions in France or abroad, or from public or private research centers.
L'archive ouverte pluridisciplinaire HAL, est destinée au dépôt et à la diffusion de documents scientifiques de niveau recherche, publiés ou non, émanant des établissements d'enseignement et de recherche français ou étrangers, des laboratoires publics ou privés. 


\section{1. Title page}

2 Effects of Chronic Exercise on Endocannabinoid System in Obese Wistar Rats Induced by High Fat Diet.

3 François-Xavier Gamelin ${ }^{1,2}$, Julien Aucouturier ${ }^{1,2}$, Fabio Arturo Iannotti ${ }^{3}$, Fabiana Piscitelli ${ }^{3}$, Enrico Mazzarella ${ }^{3}$, Teresa Aveta $^{3}$,

4 Melissa Leriche $^{1,2}$, Erwan Dupont ${ }^{1,4}$, Caroline Cieniewski-Bernard ${ }^{1,4}$, Valérie Montel ${ }^{1,4}$, Bruno Bastide ${ }^{1,4}$, Vincenzo Di Marzo ${ }^{3 \dagger}$, 5 Elsa Heyman ${ }^{1,2, \dagger}$

6

7 Authors Affiliations:

$8 \quad{ }^{1}$ Univ Lille Nord de France, F-59000 Lille France

$9{ }^{2}$ UDSL, EA4488, F-59790 Ronchin, France

$10{ }^{3} \mathrm{CNR}$, Endocannabinoid Research Group, Institute of Biomolecular Chemistry, I-80078 Pozzuoli, Italia

$11{ }^{4}$ USTL, EA4488, F-59650 Villeneuve d'Ascq, France

$12{ }^{\dagger}$ These authors share the senior authorship.

13

14 Corresponding author:

15 François-Xavier Gamelin

16 Equipe d'Accueil 4488 "Activité Physique, Muscle, Santé". Faculté des Sciences du Sport et de l'Education Physique, Université

17 Lille 2. 9, rue de l'Université 59790 Ronchin. Tel. +33 (0)3-20-88-73-80; email : francois-xavier.gamelin-2@ univ-lille2.fr

18 Short title: Endocannabinoid system and exercise 


\section{2. Abstract}

21 Objective : The endocannabinoid system is dysregulated during obesity in tissues involved in the control of food intake and energy

22 metabolism. We examined the effect of chronic exercise on the tissue levels of endocannabinoids (eCBs) and on the expression of 23 genes coding for CB1, CB2 receptors ( $C n r 1$ and $C n r 2$ respectively) in the subcutaneous (SAT) and visceral adipose tissues, and in the

24 soleus and extensor digitorim longus (EDL) muscles, in rats fed with standard or high fat diet. Methods: Twenty-eight male Wistar 25 rats were placed on high fat diet or standard diet (HFD and Ctl group respectively) during 12 weeks whereafter half of each group was 26 submitted to an exercise-training period of 12 weeks (HFD+training and Ctl+training). Tissue levels of eCBs were measured by LC27 MS while expression of genes coding for CB1, CB2 receptors were investigated by qPCR. Results: High fat diet induced an increase 28 in anandamide (AEA) levels in Soleus and EDL $(\mathrm{p}<0.02)$. In soleus of the HFD group, these results were accompanied by an 29 elevated Cnrl mRNA ( $<$ 0.05). In EDL, exercise training allowed to reduce significantly this diet-induced AEA increase ( $<<$ 30 0.005). 2-arachidonoylglycerol (2-AG) levels were decreased and increased by high fat diet in SAT and EDL respectively $(\mathrm{p}<0.04)$

31 but not affected by exercise training. Unlike in HFD+ training, 2-AG level in soleus was also decreased in HFD group comparatively

32 to $\mathrm{Ctl}$ group ( $\mathrm{p}<0.04$ ). Conclusion: The levels of eCBs and Cnrl expression are altered in a tissue-specific manner following high

33 fat diet and chronic exercise reverses some of these alterations.

34 Key words: Key words: 2-Arachidonyolglycerol, Anandamide, adipose tissue, CB1 receptor, CB2 receptor, skeletal muscle. 35 
37 Targeting the endocannabinoid system (ECS) is an interesting way to prevent weight gain as accumulating evidence highlights the 38 role of endocannabinoids (eCBs) and CB1 receptors in food intake [27] and energy metabolism regulation [37]. The ECS is a 39 complex endogenous signaling system comprising 7-transmembrane domain receptors (cannabinoid CB1 and CB2 receptors), their 40 endogenous lipid-derived ligands (the eCBs) and enzymes for ligand biosynthesis and degradation. The two most studied eCBs are $N$ arachidonoylethanolamine (AEA), also known as anandamide, and 2-arachidonoylglycerol (2-AG). AEA is only one of a large family of related bioactives acylethanolamides which includes both $N$-oleylethanolamine (OEA) and $N$-palmitoyl-ethanolamine (PEA) [2] that can share the same enzymes of AEA metabolism [20]. eCBs are not stored in cells but are synthesized on demand from arachidonic acid containing phospholipid precursors in the cell membrane through enzyme activation by multiple pathways possibly in response to elevated levels of intracellular calcium, membrane depolarization and/or receptor stimulation [19]. Enzymes known in eCBs synthesis are N-acyl phosphatidylethanolamine phospholipase D (NAPE-PLD), protein tyrosine phosphatase N22 (PTPN-22), glycerophosphodiesterase 1 (GDE-1) and $\alpha / \beta$-hydrolase 4 (ABHD4) for AEA and diacylglycerol lipase $\alpha$ (DAGL- $\alpha$ ), diacylglycerol lipase $\beta$ (DAGL- $\beta$ ) for 2-AG [12]. AEA is degraded by the fatty acid amide hydrolase (FAAH) while 2-AG catabolism is mediated by monoacylglycerol lipase (MAGL), $\alpha$ / $\beta$-hydrolase 6 (ABHD6) and $\alpha$ / $\beta$-hydrolase 12 (ABHD12)[12]. At the peripheral level, the ECS is an important factor in the modulation of energy metabolism [37]. Indeed, the entire eCB machinery is expressed in peripheral tissues involved in energy balance regulation such as white adipose tissue and skeletal muscle [37]. In adipocytes, CB1 activation promotes fatty acid de novo biosynthesis, triglycerides accumulation by activating glucose uptake, fatty acid synthase and inhibits lipolysis by decreasing mitochondrial biogenesis [41, 43]. This adipocyte endocannabinoid tone is subject to negative feedback control by hormones and peroxisome proliferator-activated-receptors PPAR, including leptin [14], insulin [30], PPAR $\gamma$ [28] and PPAR [47]. In the skeletal muscle, CB1 stimulation reduces glucose uptake, insulin sensitivity [22, 23], oxidative pathways and mitochondrial biogenesis [6], thus slowing down energy expenditure [38]. Taken together, these data suggest that ECS activation induce an energy balance toward energy storage.

Recent data demonstrate a link between obesity development and ECS deregulation in different tissues involved in metabolism regulation [29]. This deregulation is usually characterized by an ECS overactivity as an increase in eCB levels, modifications of CB1 expression and alterations in enzymes involved in eCB biosynthesis and degradation were observed during obesity [37]. In the visceral fat of diet-induced obese mice, elevated levels of eCBs have been observed [8, 28, 39], but reduced levels are instead found in the subcutaneous white adipose tissue of these animals [39]. Regarding the lipogenic action of CB1 receptors, the unbalance of the ECS between subcutaneous and visceral white adipose tissues might eventually contribute to accumulation in the latter at the expenses of the former, and, hence, to the several metabolic disorders associated with visceral obesity [38]. In obese rodent skeletal muscle, AEA and 2-AG might be also increased by alterations in their biosynthetic or degrading enzymes possibly contributing to the impairment in glucose uptake and mitochondrial oxydations [19]. Thus this overactivity in peripheral tissues involved in energy homeostasis may participate in excessive and/or ectopic fat accumulation, insulin sensitivity impairment and related metabolic disorders [14, 29]. Whether ECS deregulation is a consequence or a cause of obesity, it represents a primary target for the treatment of abdominal obesity and associated metabolic changes [33].

1 A healthy lifestyle approach could be effective to diminish ECS overactivity [13] and may represent a safer alternative than the 2 pharmaceutical approaches. In subcutaneous and visceral adipose tissues from rodents, chronic exercise limits the CB1 gene 73 expression increase induced by high fat diet [47]. Thus, it is possible that chronic physical activity counteracts ECS deregulation in 74 these tissues. However this potential beneficial adaptation of the ECS remains to be confirmed in tissues involved in energy balance 75 control and adaptable to exercise, such as the skeletal muscle [35]. In obese volunteers, exercise improves muscle metabolism by 6 enhancing glucose uptake, insulin sensitivity, oxidative pathways and mitochondrial biogenesis [35]. These elements are also 7 negatively regulated by ECS and might be disturbed by CB1 overactivity during obesity [6, 23, 41]. Thus, it could be hypothesized 8 that chronic exercise will reverse obesity-induced ECS alterations in skeletal muscle. 
79 This study aimed at identifying the changes in the tissue concentrations of AEA and 2-AG as well as of two AEA congeners, OEA 80 and PEA, together with corresponding alterations in the expression of genes encoding Cnrl and Cnr2 for eCB receptors (CB1, CB2) 81 and enzymes involved in the anabolic (ABHD4, GDE-1, NAPE-PLD and PTNP-22, for AEA, OEA and PEA; DAGL- $\alpha$ and DAGL-

$82 \beta$, for 2-AG) and catabolic (FAAH, for AEA, OEA and PEA; ABHD6, ABHD12 and MAGL, for 2-AG) pathways of the eCBs, after 83 regular endurance training in the subcutaneous (SAT) and visceral (VAT) adipose tissues, and in the slow-type soleus and fast-type 84 extensor digitorim longus (EDL) muscles of Wistar rats fed with a standard or a high fat diet. Finally, we analyzed the expression of 85 the transient receptor potential vanilloid type-1 (TRPV1) channel, which is activated by eCBs as well as by AEA congeners, and is 86 considered a ionotropic receptor for eCBs [49]. 


\section{4. Methods}

\section{Animals and experimental procedures}

90 Twenty-eight male Wistar rats (3 weeks old) were housed in groups of three per cage. After one week of acclimatization, rats were

91 divided in 2 groups and fed with a standard diet or a high fat diet in order to induce obesity during 24 weeks. After 12 weeks, half of

92 the rats were submitted to 12 weeks of exercise training (Ctl+training, $n=7$ and HFD+training, $n=7$ ). The second half of the rats

93 remained untrained for 12 weeks ( $\mathrm{Ctl}$ and HFD groups for rats on standard $(\mathrm{n}=7)$ and high fat $(\mathrm{n}=7)$ diets respectively). Before and

94 after the training period, Ctl+training and HFD+training performed a MAV (Maximal Aerobic Velocity) test on the treadmill. Five

95 days before sacrifice, all rats were subjected to an oral glucose tolerance test (OGTT). At the end of the training period, all rats were

96 anesthetized with an intraperitoneal injection of sodium pentobarbital $(60 \mathrm{mg} / \mathrm{kg}$ ). Soleus (slow-type postural muscle) and EDL (fast-

97 type muscle) muscles, epididymal VAT, inguinal SAT and blood were collected.

98 All procedures described were approved by both the Agricultural and Forest Ministry and the National Education Ministry

99 (Veterinary service of health and animal protection).

\section{Diet-induced obesity}

102 Rats were fed ad libitum with two different types of diet during the 24 weeks of the experimentation:

- A high fat diet (Purified Diet $231 \mathrm{HF}$, Safe, Augy. France) with an energy equivalent of $5.05 \mathrm{kcal} . \mathrm{g}^{-1}$. It contained $26.9 \%$ of proteins, $39.7 \%$ of lipids and $10.1 \%$ of carbohydrates.

- A standard diet with an energy equivalent of $2.90 \mathrm{Kcal}^{-1}$. It contained $16 \%$ of proteins, $3 \%$ of lipids, $60 \%$ of carbohydrates and $21 \%$ of other components (fiber, mineral, humidity).

Fatty acid compositions of the two diets were provided by the manufacturer (Safe, Augy. France) and are described in table 1. Food 109

\section{Maximal aerobic velocity test}

111 Animals in the HFD+training and Ctl+training were familiarized with treadmill running (L810, Bioseb. France) during 10 min for 5 days at a velocity of $20 \mathrm{~cm} \cdot \mathrm{s}^{-1}$ and a $0^{\circ}$ slope. Electric shocks were used sparingly to motivate the rats to run. After the familiarization period, $\mathrm{Ctl}+$ training and HFD+training groups performed a graded exercise test to voluntary exhaustion. The test started at $20 \mathrm{~cm} \cdot \mathrm{s}^{-1}$ for $5 \mathrm{~min}$, followed by speed increment of $3 \mathrm{~cm} \cdot \mathrm{s}^{-1}$ every 3 minutes until the animal could no longer keep up with the treadmill speed. Exhaustion was reached when animal sat longer than $10 \mathrm{~s}$ on electric shock grid. MAV was defined as the velocity of the last 3 min stage completed. The same protocol was repeated 1 week before rats sacrifice to determine the change in MAV with exercise training (two days before the OGTT).

\section{Exercise training program}

The day after the baseline MAV test, Ctl+training and HFD+training groups started the 12-week exercise training period that consisted of treadmill running for 1hour/day, 5 days/week at an intensity set between $70-80 \%$ of the MAV. The intensity was increased by $1 \mathrm{~cm} \cdot \mathrm{s}^{-1}$ every week to take into account the adaptations to exercise training. Animal exercised at the same hour of the day at the end of the room dark cycle $(7: 30 \mathrm{am})$. Control groups were in the same room during the training session and handled in the same way to induce a similar stress level. Three days before the sacrifice, exercise training was stopped to avoid the acute effect of exercise, fatigue or stress. \\ 127 Oral Glucose Tolerance Test}

128 Five days before sacrifice, the animals were fasted overnight. Basal blood glucose level, defined as T0, was determined using an automatic glucometer (Accu-Chek Performa; Roche Diagnostics) before oral administration (4 ml. $\mathrm{kg}^{-1}$ of body weight) of a D-glucose solution (50\%). Tail vein blood glucose was then measured at 30, 60, 90, 120 min after the administration. Total Area under the curve (AUC) was calculated using the trapezoidal method [36]. 


\section{Samples collection}

134 The day before the end of the experiment, rats were fasted in order to obtain the same nutritional state for each. For all groups, soleus,

135 EDL, SAT from the inguinal region and VAT from the epididymal fat were quickly removed from animals anesthetized with 136 pentobarbital sodium (60 mg. $\mathrm{kg}^{-1}$ of body weight, intraperitoneal injection). Samples were weighed, immediately frozen in liquid 137 nitrogen and stored at $-80^{\circ} \mathrm{C}$ until analyses.

138 Blood samples were collected by cardiac puncture and then directly drawn into pre-cooled 5-mL EDTA (Ethylenediaminetetraacetic acid) tubes. The later were immediately centrifuged (less than 5 min after sampling) and plasma was removed and frozen $\left(-80^{\circ} \mathrm{C}\right)$ until analysis.

\section{Plasma analyses}

143 The fasting glucose concentration in plasma was measured using a commercially available colorimetric assay kit (Cayman Chemical 144 Company, USA). Fasting plasma insulin was determined using a commercially available rat insulin enzyme immunoassay kit (SPI145 BIO, France).

\section{Measurements of tissue eCBs}

The extraction, purification, and quantification of eCBs from tissues have been performed as previously described [20]. Briefly, the tissues were dounce-homogenized and extracted with chloroform/methanol/Tris-HCl $50 \mathrm{mmol} . \mathrm{l}^{-1} \mathrm{pH} 7.5$ (2:1:1, vol/vol) containing internal standards ([2H]8 AEA; [2H]5 2-AG, $[2 \mathrm{H}] 5$ PEA and [2H]4 OEA 5 pmol each). The lipid-containing organic phase was dried down, weighed, and pre-purified by open-bed chromatography on silica gel. Fractions were obtained by eluting the column with 99:1, 90:10 and 50:50 (v/v) chloroform/methanol. The 90:10 fraction was used for AEA, 2-AG, PEA and OEA quantification by liquid chromatography - atmospheric pressure chemical ionization - mass spectrometry by using a Shimadzu high-performance liquid chromatography apparatus (LC-10ADVP) coupled to a Shimadzu (LCMS-2020) quadruple mass spectrometry via a Shimadzu atmospheric pressure chemical ionization interface as previously described [20]. The amounts of analyses in tissues quantified by

\section{RNA purification and quantitative real-time PCR (qPCR)}

159 Total RNA was isolated from native tissues by use of the TRI-Reagent (Sigma-Aldrich, Milan, Italy), reacted with DNase-I (1 U/ml;

160 Sigma-Aldrich) for $15 \mathrm{~min}$ at room temperature, and followed by spectrophotometric quantification. Final preparation of RNA was considered DNA- and protein-free if the ratio between readings at $260 / 280 \mathrm{~nm}$ was $\geq 1.7$. Isolated mRNA was reverse transcribed by use of SuperScript III Reverse Transcriptase [Life Technologies, Monza (MI), Italy]. The quantitative real-time PCR was carried out in CFX384 real-time PCR detection system [Bio-Rad, Segrate (MI), Italy] with specific primers [20] by the use of SYBR Green master mix kit [Bio-Rad, Segrate (MI)] (See table 2 for primers sequences).

Samples were amplified simultaneously in quadruplicate in one-assay run with a non-template control blank for each primer pair to control for contamination or primer-dimers formation, and the ct (cycle threshold) value for each experimental group was determined. The housekeeping gene (the hypoxanthine-guanine phosphoribosyltransferase, hprt) was used as an internal control to normalize the ct values, using the $2-\Delta \mathrm{Ct}$ formula. Differences in mRNA content between groups were as expressed as $2-\Delta \Delta \mathrm{Ct}$.

\section{Statistical analyses}

172 Shapiro-wilk test. Two or 3-way ANOVAs were used to evaluate the evolution of weight during the first 12 weeks of the experiment 173 (Time $\mathrm{x}$ Diet), the evolutions of weight (Time $\mathrm{x}$ Diet $\mathrm{x}$ Exercise) and MAV (Time $\mathrm{x}$ Diet) during the exercise-training period and 174 mean caloric intake during each 12-week period (the first 12 weeks, Time $\mathrm{x}$ Diet and the further 12 weeks training period, Time $\mathrm{x}$ 175 Diet x Exercise). Multiple comparisons were made with the Newman-Keul post-hoc test. A two-way ANOVA was used to evaluate 176 the effects of diet, exercise training and the diet x exercise interaction on metabolic parameters (fasting glucose, insulin, AUC during 
177 OGTT), and on tissue eCBs and congeners levels. Multiple comparisons were made with the Bonferroni post-hoc test if significant 178 main effects or interaction were observed with ANOVA. Concerning gene expression data, ctl group was compared with other groups 179 by use of the Mann-Whitney U test. Statistical significance was set at $\mathrm{p}<0.05$ for all analyses. All calculations were made with 180 Statistica 6.0 (Statsoft, Tulsa, USA). 
183 Effect of diet and/or exercise on body weight, food intake, maximal aerobic velocity, basal glucose and insulin levels, and glucose tolerance (Table 3)

185 Body mass increased with time and this all the more in case of high fat diet throughout the 12 and 24 weeks of study. During the second period (12 to 24 weeks), exercise training slowed down the time-induced body mass gain. Mean caloric intake per day and per rat were increased in rats on high fat diet but the increase induced by time slowed down with this diet.

188 MAV was measured only in exercise trained groups to avoid a familiarization in Ctl and HFD groups that could affect the results.

189 Two-way ANOVA for MAV revealed that MAV was reduced by high fat diet but that exercise training increased MAV in a 190 comparable extent in both diets.

191 Plasma insulin levels were neither affected by diet nor by exercise training. Fasting plasma glucose concentrations were increased

192 by high fat diet but this increase was strongly reduced by exercise training. Consequently, at the end of the experimentation, the 193 HFD group was exposed to much higher plasma glucose concentrations compared to all the other groups, included the 194 HFD+training group. Glucose AUC during the OGTT was also significantly increased by high fat diet but without significant 195 protecting effect of exercise training.

196 Effect of diet and/or exercise on AEA, 2-AG, PEA, OEA levels (Table 4) and the expression of genes coding for eCB 197 receptors and enzymes implicated in the synthesis or degradation of eCBs in adipose (Figure 1) and skeletal muscle (Figure 198 2) tissues.

\section{Adipose tissue}

200 In SAT, high fat diet decreased 2-AG whereas exercise training or combination of both had no effect on this eCB nor on AEA and its congeners levels. Despite this diet effect on 2-AG, the mRNA levels of the enzymes for 2-AG biosynthesis or degradation were not affected significantly in HFD group (Fig.1c). While chronic exercise did not change the expression of genes coding for enzymes involved in AEA and 2-AG metabolism in lean rats, we found a significant increase in the expression of genes coding for GDE-1, FAAH, DAGL- $\alpha$, ABHD12 and MAGL when exercise training was combined with high fat diet in SAT (Fig.1b and 1c). Concerning the expression of genes coding for cannabinoid receptors in SAT, high fat diet in lean rats reduced significantly Cnrl mRNA levels (Fig.1a). However, when chronic exercise was added to high fat diet, this diet effect was completely reversed with Cnrl mRNA levels strongly enhanced in HFD+training group (Fig.1a). Trpvl mRNA levels were not affected by diet, but were increased by exercise training in both lean and high fat diet rats compared to the ctl group (Fig.1a).

In VAT, as seen in table 4 and figure 1, high fat diet or exercise training or the combination of both did not induce significant changes in eCBs or AEA congeners levels but affected gene expression of eCBs biosynthetic or degradation enzymes. Twentyfour weeks of high fat diet increased significantly Gde-1 and Ptpn-22 mRNA levels in sedentary rats (Fig. 1e). This increase was not observed anymore for Gde-1 mRNA levels in the HFD + training group, but was always present for Ptpn-22 in the ctrl+training and HFD+training groups (Fig. 1e). Expression of FAAH, the major AEA degrading enzyme (Fig. 1e), was significantly higher in HFD, ctl+training and HFD+training groups as compared to ctl. High fat diet increased significantly DAGL- $\alpha$ and ABHD-12 mRNA in sedentary rats (Fig.1f). This increase in Abhdl2 gene expression was also observed in ctl+training group but not in the HFD+training group (Fig.1f). Exercise combined with high fat diet had no effect on enzyme gene expression involved in 2-AG metabolism even though MAGL mRNA was slightly but non-significantly increased (Fig.1f). While cnrl gene expression was significantly increased in all groups comparatively to ctl group in VAT, cnr2 mRNA level was significantly decreased in all experimental conditions (Fig.1d). Trpv1 mRNA levels was only increased significantly in HFD group 


\section{Skeletal muscles}

223 In the soleus, 24 weeks of high fat diet induced significant higher AEA and OEA concentrations whereas exercise training had no

224 significant effect. Contrary to AEA and its congeners, soleus 2-AG concentrations were affected when diet was paired with

225 exercise training. Between group comparison indicated that HFD group presented significant lower 2-AG concentration than Ctl

226 group and this 2-AG decrease was no longer observed in the HFD+ training group.

227 The increase of AEA levels induced by high fat diet in the soleus was accompanied by the modification of the gene expression of

228 enzymes involved in AEA metabolism in HFD group (Fig. 2b). We observed higher levels of Abhd4 mRNA and lower levels of

229 Ptpn-22 and Faah mRNA. The altered mRNA levels of these genes, especially Abhd4 and Faah could explain the increase in AEA

230 and OEA levels induced by high fat diet. However, they were also observed following exercise program in lean and obese rats, in

231 which exercise training had no significant effect on AEA and OEA levels. Concerning enzymes potentially involved in 2-AG

232 metabolism (Fig. 2c), the mRNA of Abhd6 was overexpressed in HFD, Ctl+training and HFD+training groups, whereas Abhd12

233 mRNA was less expressed in HFD and Ctl+training group. Magl mRNA expression was also affected by exercise and was lower

234 in $\mathrm{Ctl}+$ training and HFD+training groups. $\mathrm{Cnrl}$ gene expression in soleus was significantly increased with HFD compared to Ctl

235 group, and this difference was no longer observed with exercise training (Fig. 2a).

236 In the EDL, AEA and 2-AG concentrations were increased with high fat diet. Whereas exercise had not effect on 2-AG level, it 237 induced a significant decrease in AEA. Moreover, it allowed to reduce the AEA increase induced by high fat diet. Thereby post 238 hoc test revealed that HFD group presented a significant higher AEA concentration than all other groups. The increase in AEA 239 levels in HFD group was again accompanied by a significant increase in Abhd4 mRNA levels and a decrease in Faah mRNA 240 levels, as shown in figure 2e. In this tissue, however, only the increase in Abhd4 mRNA level was still observed with exercise in

241 Ctl+training and HFD+training groups, whereas the decrease in Faah levels was not, thus possibly explaining the reversal of the

242 elevation of AEA levels by chronic exercise. Gene expression of Ptpn22 (Fig. 2e) was significantly increased with exercise only in

243 lean rats. Neither high fat diet nor exercise training nor the combination of both affected gene expression of enzymes involved in 244 2-AG metabolism (Fig. 2d).

245 As shown in figure 2a, the mRNA expression of genes coding for CB1, CB2 and TRPV1 in EDL were not altered by high fat diet, 246 exercise nor the combination of both. 
249 The aim of this study was to examine the effect of chronic exercise on the tissue levels of eCBs and two AEA congeners and on the expression of genes coding for $\mathrm{CB} 1, \mathrm{CB} 2$ receptors and the enzymes responsible for synthesis and degradation of eCBs in adipose tissues and skeletal muscles, in Wistar rats fed with standard or high fat diet. Our results can be summarized by stating that high fat diet or exercise training induced different changes in eCB levels and/or eCB receptor expressions in all tissues analyzed. Noteworthy, the changes induced by high fat diet were tissue-specific and some of these changes were reversed by exercise training.

As expected, rats fed with a high fat diet exhibited abnormalities that precede diabetes as indicated by higher fasting glucose levels and glucose intolerance during an OGTT. Basal insulin levels remained even so unchanged with the high fat diet regimen, which may reflect a relative deficiency of insulin secretion. However, this finding must be taken with caution as metabolic perturbations induced by HFD depend on the dietary regimen and the animal model used [17]. We confirmed that endurance exercise improves MAV and metabolic syndrome risk factors such as basal glycemia and weight gain in rat model of diet induced obesity (DIO) [42]. Nevertheless, although glucose intolerance during the OGTT seemed to be slightly improved in the HFD +training group, the difference with the HFD group did not reach statistical significance.

\section{Effect of High Fat Diet on the ECS in the adipose tissue and skeletal muscle.}

Elevated levels of eCBs and Cnrl gene expression have been observed in the visceral fat of DIO rodents [39, 47] but reduced eCBs levels are instead found in the SAT of these animals [39]. This is in line with our present results of decreased 2-AG levels and Cnrl mRNA levels in the SAT, and of increased Cnrl mRNA levels in the VAT, of rats fed with high fat diet. The 2-AG decrease in SAT induced by high fat diet is difficult to explain regarding mRNA expression of its biosynthetic and/or degrading enzymes in the 2 groups on high fat diet. While no changes appeared in HFD group, biosynthetic (dagl- $\alpha$ ) and degrading enzyme (abhd12, magl) mRNA levels were overexpressed at the same time in the HFD+training group. Thus, this lack of consistency between the two HFD groups suggests that more than mRNA expression of enzymes, enzymatic activities and eCB precursors may be more involved in the 2-AG decrease induced by high fat diet. Whatever, these results confirm the existence of an unbalanced eCB tone between these two adipose tissue depots in favor of VAT. Regarding the inhibitory effect of insulin on 2-AG and the insulin resistance that occurs during obesity in visceral more than subcutaneous adipocytes, these 2-AG unbalance might be the result of the loss of the possible insulin inhibition of eCBs levels in VAT [39]. Thus this lack of CB1 stimulation by the 2-AG decrease in SAT may impair adipocyte glucose uptake [43] and then participating to the hyperglycemia observed in rat submitted to high fat diet. Moreover the unbalanced eCB tone might impair lipogenesis in SAT and its capacity to buffer energy surplus leading to fat accumulation in favor of VAT and other tissues not suited for lipid storage and hence to the metabolic disorders therewith associated [45].

In agreement with previous results [11,39], we have confirmed that both SAT and VAT express mRNA coding for the CB2 receptor. Activation of the CB2 receptor in adipose tissue might promote tissue inflammation by increasing macrophage infiltration and the related inflammatory response and contribute to the development of insulin resistance [11]. Even if CB2 receptor are expressed in adipocytes [39], the presence of this receptor in the adipose tissue is mainly attributed to the stromal vascular fraction [11]. Deveaux et al.[11] have already reported an increase in $\mathbf{C n r 2}$ expression in adipose tissue of mice under high fat diet. Interestingly, this $\mathrm{Cnr} 2$ expression increase was the result of macrophage infiltration rather than a raise in adipocyte $\mathrm{Cnr} 2$ expression. In our study, while one may expect an increase in Cnr2 mRNA in the epididymal adipose tissue in the HFD group, accompanying the probable obesity-associated macrophage infiltration as already observed by Deveaux et al. [11] in mice, we instead observed a decrease. We did not measure macrophage infiltration or adipose tissue inflammation, but the possible lack of inflammation in our study could not justify the decrease in $C n r 2$ mRNA levels, as no change in expression would be expected in this 
289 case. Therefore, it is possible that the observed decrease is due to high fat diet-induced non-inflammatory regulatory events in these cells. Further investigations are required to explain this phenomenon.

291 Importantly, we also observed changes in the expression of Trpv1 mRNA in the VAT during high fat diet. TRPV1 is known to

292 be binded by AEA and to be the molecular integrator of inflammatory mediators [40]. Recent studies underlined also the

293

294

Skeletal muscle plays a crucial role in energy homeostasis regulation by being the primary site of glucose disposal and fatty acid oxidation [19]. This role could be altered by ECS dysregulation in obesity and/or hyperglycemia, as suggested by the literature [6, 15, 24, 29]. Our results confirmed the study of Iannotti et al.[20] in obese Zucker fa/fa rats. We indeed observed that 24 weeks of high fat diet increased AEA levels in both the soleus and EDL. As CB1 stimulation reduces glucose uptake, insulin sensitivity [22, 23], oxidative pathways and mitochondrial biogenesis [6], these EDL and soleus AEA increases may participate to the glucose intolerance observed in rats under high fat diet. AEA increases are in line with the lower expression of the gene coding for FAAH, the main AEA-degrading enzyme [37] and with the higher mRNA levels of Abhd4, coding for an AEA-biosynthetic enzyme (ABHD4) in HFD group. Although Ptnp22 mRNA levels (coding for PTNP22 another potential AEA-biosynthetic enzyme) were instead decreased in the soleus, this may not influence significantly AEA levels, as PTNP22 involvement in the biosynthesis of the eCB has so far been shown only in vitro [25].

Contrary to AEA, the levels of 2-AG in the soleus were decreased in the HFD group compared to other groups. Previous studies [20, 29] have focused on skeletal muscle $2-A G$ level in rodent obesity models and found conflicting results (i.e. no change or increase). In the present study, the observed decrease of 2-AG concentrations in soleus was probably due to the strong increase of the expression of the gene coding for ABHD6 (Abhd6), a 2-AG degrading enzyme. These results confirm the existence of a lower rate of production of 2-AG in the skeletal muscle, suggested by Crespillo et al. [9], who reported a decrease and an increase in expression of genes coding for DAGL $\alpha$ and MAGL, respectively. However, a similar effect on 2-AG levels is not always observed in rodents with DIO [20, 29] and we found a significant increase in EDL with high fat diet. These discrepancies among studies may be explained by the influence of the diet, the animal species and the presence of metabolic disturbances on eCB levels [29, 37]. Also muscle composition (i.e. slow $v s$. fast-twitch muscle fibers) might be another factor affecting ECS dysregulation during obesity and/or hyperglycemia. Indeed, in the present study, the levels of eCBs and congeners, as well as the expression of genes related to eCB enzymatic machinery, were differentially regulated in the soleus and EDL, which are a slow and a fast-twitch muscle, respectively [31]. This difference in ECS response to diet between slow and fast twitch muscles was also observed at the level of eCB receptor expression. As in previous studies conducted in DIO rodents [20, 32], CB1 mRNA expression was increased in the soleus, confirming the existence of ECS alteration, which reduces insulin signaling, glucose uptake and oxygen consumption in this tissue [6, 23, 26]. However, a different situation was found in the EDL, where we observed no change in CB1 (or CB2) mRNA expression. Likewise, in the abdominal muscle, which has a mixed fiber composition, Crespillo et al. [9] detected a trend towards a decrease in CB1 mRNA, and a significant decrease in CB2 mRNA expression, after a 10-week high fat diet period. Thus muscle ECS response to high fat diet seems to depend on muscle fiber composition and may induce specific metabolic responses. Indeed insulin sensitivity alteration induced by CB1 activation [22, 23], and the overexpression in CB1 mRNA in soleus may explain in part the larger decrease in insulin sensitivity generally observed in slow twitch fibers during chronic hyperglycemia [18]. More investigations are needed to confirm that the ECS is involved in metabolic specific muscle responses to high fat diet. 
Taken together these ECS tone unbalance between adipose tissues and ECS muscle overactivity might participate in weight gain and in the glucose intolerance observed in rats submitted to high fat diet. Regarding the importance of 1) insulin muscle sensitivity during glucose challenge [10], 2) muscle fiber composition on insulin resistance [18] and 3) glucose uptake and insulin sensitivity reduction induced by CB1 activation [22, 23], we can speculate that ECS alteration in muscle mainly composed by slow twitch fibers could be more deleterious for insulin sensitivity than in fast twitch muscle.

\section{Effect of Exercise on ECS in adipose tissues and skeletal muscles of lean and obese rats}

Chronic exercise alone had no effect on eCB tone in the SAT of lean rats, whereas it upregulated the mRNA expression of some eCB biosynthetic and degrading enzymes and prevented the decrease of Cnrl mRNA level induced by the high fat diet. Yan et al. [47] have already shown that chronic exercise alone does not affect Cnrl expression in the SAT of lean rats. However, they observed also a normalization of Cnrl mRNA levels when they combined regular exercise to high fat diet in comparison to diet alone. Exercise training tended also to prevent the $2-\mathrm{AG}$ decrease induced by high fat diet in SAT but non-significantly ( $\mathrm{p}=0.06$ ) and thus, the deleterious unbalanced ECS tone in favor of visceral fat accumulation. This effect might be induced by the leptin level decrease observed with exercise in obese people [34] that might reduce leptin inhibitory effect on 2-AG [14]. This is in line with previous study [5] that observed 2-AG level normalization in SAT after weight loss and fat mass decrease in obese people. Indeed fat mass loss induced also a leptin secretion decrease in adipose tissue [4] that might contribute to 2-AG level normalization. We did not measure fat mass, and even if the body weights of the HFD and HFD+training groups were not significantly different we can speculate that training period has decreased fat mass and increased lean mass.

Concerning the VAT, chronic exercise did not reverse the upregulation of $C n r l$ and the downregulation of $C n r 2$ mRNA induced by the high fat diet. However, Yan et al. [47] observed a decrease in Cnrl gene expression when they added chronic exercise to HFD. This discrepancy with our study could be explained by differences in the two protocols used. In our study, rats were exposed to exercise training after a high fat diet period of 12 weeks, whereas Yan et al. [47] submitted their rats to exercise from the beginning of the high fat regimen. Thus, it is likely that exercise might prevent the changes in eCB receptor expression induced by high fat diet in the VAT, but not reverse them if they are already present.

Training reversed Trpv1 mRNA upregulation observed in VAT in HFD group. Considering the TRPV1 protective effect against ECS overactivation in the VAT during the high fat diet-induced obesity, it is not surprising to observe a normalization of Trpv1 mRNA level as exercise might also reverse the negative effects of the high fat diet on this adipose depot. We also observed changes in the expression of Trpv1, which was upregulated by training in both lean and high fat diet rats in the SAT. TRPV1 might become upregulated by exercise in the SAT in order to enhance energy expenditure [21] in this adipose depot, regardless of the diet.

Importantly, twelve weeks of regular exercise reversed some eCB dysregulation induced by high fat diet in the skeletal muscle. In the soleus, the 2-AG decrease induced by high fat diet was not longer observed in HFD+training group probably due to a decrease in magl expression, the gene of the key enzyme in the hydrolysis of this endocannabinoid. Cnrl mRNA upregulation in the HFD group was prevented by exercise training in the soleus muscle. This is in agreement with data by Wiklund et al. [46] who reported a decrease in CB1 protein expression in the skeletal muscle of mice fed with a high fat diet after an aerobic exercise period. Thus, this decreased in Cnrl mRNA expression in the soleus might participate to an improvement in glucose metabolism previously observed during chronic antagonism of $\mathrm{CB} 1$ by increasing muscle glucose uptake [22, 26]. However, it is worth noting that similarly to the Ctl+training group, AEA levels tended to remain elevated in the HFD+training, suggesting an additive and positive effect of chronic exercise and high fat diet on AEA. Moreover the gene expression of several eCB biosynthetic (PTPN-22) and degrading (FAAH, ABHD12, MAGL) enzymes in Ctl+training and HFD+training was altered in the same manner as in the HFD group, in agreement with a higher AEA turnover in the skeletal muscle. This potential similarity between HFD and exercise is surprising as it suggests that chronic exercise, by increasing muscle AEA levels, could reduce glucose uptake, insulin sensitivity [22, 23], oxidative pathways and mitochondrial biogenesis [6] and at least negatively influence muscle metabolism. However, some studies [6, 15] have already demonstrated that AEA may also exert beneficial effects on markers of muscle glucose metabolism, mitochondrial biogenesis 
and oxidative mitochondrial capacity independently of cannabinoid receptors [35]. Nevertheless these beneficial adaptations are the consequence of an acute administration of a high dose of AEA, and not of a chronic treatment with the eCB, such as during increased ECS tone in obesity.

Concerning the EDL, a fast twitch muscle, exercise training was not accompanied by a decrease in faah expression in obese or lean rats as rather observed during high fat diet alone. These different adaptations of the main AEA degrading enzyme to exercise with or without high fat diet vs. diet alone might explain the decrease in AEA level observed with training in this skeletal muscle. Contrary to the soleus, exercise decreased AEA level in EDL that might suggest a better improvement in glucose metabolism in fast twitch muscle regarding the AEA effect on skeletal muscle glucose transport activity and muscle insulin sensitivity. This is in line with previous studies that have demonstrated that the exercise-induced increase in skeletal muscle insulin sensitivity was larger in fast twitch muscle $[7,16]$.

Taken together, normalizations of the expression of the gene coding for the CB1 receptor in the soleus and of the AEA levels in the EDL might participate in improvement in the basal glycemia observed in the HFD+training group. Indeed, previous studies have already demonstrated an improvement in skeletal muscle glucose metabolism when reducing eCB tone with a CB1 antagonist [22, 23, 26]. However ECS response to exercise in lean and obese rats seems to be different according the skeletal muscle type. More investigations are needed to understand the meaning of different eCB remodeling induced by exercise in slow and fast twitch muscles.

Our study has several limitations. First, we did not assess protein level of receptors or enzymes and their functionalities. Second, MAV was measured to show exercise training efficiency. Nevertheless the use of skeletal muscle, adipose or plasma tissue remodeling markers would have been more relevant to highlight the effect of training or diet and their associations with ECS changes. Third, recent findings showed that eCBs and their receptors are sensitive to diet composition and more particularly to polyunsaturated fatty acids (PUFA)[44]. Dietary PUFA induced a remodeling in the phospholipid composition of cell membranes and changed substrate availability for the biosynthesis of eCBs [44]. Alvheim et al. [1] have already observed an increase in arachidonic acid (the substrate for the eCBs) and thus in AEA and 2-AG levels in liver of mice fed with a diet enriched in linoleic acid. In our study, high fat diet used was also mainly composed by this fatty acid, which could have increased arachidonic acid availibility and thus influenced the tissue eCB levels [1]. Thus eCB changes presented in our study may be the result of both metabolic disorders associated with obesity and the diet-induced increase in eCB precursors.

\section{Conclusion}

In summary, we have confirmed here that weight gain and perturbations of glucose metabolism are accompanied by changes in the ECS in major tissues involved in metabolism regulation which are adipose tissue and skeletal muscle. These alterations are tissuesspecific and, notably, for the muscle we observed here for the first time a difference in HFD-induced ECS dysregulation between glycolytic and oxidative muscles. Interestingly, adding chronic exercise to HFD reverses some of these alterations in the different tissues. Nevertheless, depending on the tissue, exercise per se could mimic the effect of HFD on the levels of eCBs and/or their receptors and/or their anabolic and catabolic enzymes. This seemingly paradoxical response is observed in the VAT and, in part, in the oxidative soleus muscle, and highlights the need to investigate the role of the ECS also in the beneficial metabolic adaptations induced by chronic exercise. 


\section{7. List of abbreviations}

412 2-AG: 2-arachidonoylglycerol

413 ABHD4 : $\alpha / \beta$-hydrolase 4

414 Abhd4 : $\alpha$ / $\beta$-hydrolase 4 gene

415 ABHD6 : $\alpha / \beta$-hydrolase 6

416 Abhd6: $\alpha / \beta$-hydrolase 6 gene

417 ABHD12 : $\alpha / \beta$-hydrolase 12

418 Abhd12: $\alpha / \beta$-hydrolase 12 gene

419 AEA: anandamide

420 CB1: Cannabinoid receptor 1

421 CB2: Cannabinoid receptor 2

422 Cnrl: Cannabinoid receptor 1 gene

423 Cnr2: Cannabinoid receptor 2 gene

424 Ctl: Control group

$425 \mathrm{Ctl}+$ training: Exercise training + standard diet group

426 DAGL- $\alpha$ : Diacylglycerol lipase $\alpha$

427 Dagl- $\alpha$ : Diacylglycerol lipase $\alpha$ gene

428 DAGL- $\beta$ : Diacylglycerol lipase $\beta$

429 Dagl- $\beta$ : Diacylglycerol lipase $\beta$ gene

430 DIO: diet induced obesity

431 eCBs: Endocannabinoids

432 ECS: Endocannabinoid system

433 EDL: Extensor digitorum longus

434 EDTA: Ethylenediaminetetraacetic acid

435 FAAH : Fatty acid amide hydrolase

436 Faah : Fatty acid amide hydrolase gene

437 GDE-1: Glycerophosphodiesterase 1

438 Gde-1: Glycerophosphodiesterase 1 gene

439 HFD: High fat diet group

440 HFD+training: Exercise training + high fat diet group

441 MAGL: Monoacylglycerol lipase

442 Magl: Monoacylglycerol lipase gene

443 MAV : Maximal aerobic velocity

444 NAPE-PLD: N-acylphosphatidylethanolamine-phospholipase D

445 Nape-pld: N-acylphosphatidylethanolamine-phospholipase D gene 
446 OEA: N-oleoylethanolamine

447 OGTT : Oral glucose tolerance test

448 PEA: $N$-palmitoyl-ethanolamine

449 PPAR: Peroxisome proliferator-activated-receptor

450 PTPN-22: Protein tyrosine phosphatase N22

451 Ptpn-22: Protein tyrosine phosphatase N22 gene

452 PUFA: polyunsaturated fatty acids

453 SAT: Subcutaneous adipose tissue

454 RNA: Ribonucleic acid

455 mRNA : Messenger RNA

456 TRPV1: Transient receptor potential cation channel subfamily V member 1

457 Trpv1: Transient receptor potential cation channel subfamily V member 1 gene

458 VAT: Visceral adipose tissue 
460 9. Acknowledgments

461 The authors thank P. Barbez, E. Leclair and J. Gamain for their advices and technical assistances.

462

463 10. Funding

464 This research did not receive any specific grant from any funding agency in the public, commercial or not-for-profit sector. 465

466 
1. Alvheim AR, Malde MK, Osei-Hyiaman D, Lin YH, Pawlosky RJ, Madsen L, Kristiansen K, Froyland L \& Hibbeln JR (2012) Dietary linoleic acid elevates endogenous 2-AG and anandamide and induces obesity. Obesity (Silver Spring) 20:1984-1994

2. Artmann A, Petersen G, Hellgren LI, Boberg J, Skonberg C, Nellemann C, Hansen SH \& Hansen HS (2008) Influence of dietary fatty acids on endocannabinoid and $\mathrm{N}$-acylethanolamine levels in rat brain, liver and small intestine. Biochim Biophys Acta 1781:200-212

3. Baboota RK, Singh DP, Sarma SM, Kaur J, Sandhir R, Boparai RK, Kondepudi KK \& Bishnoi M (2014) Capsaicin Induces "Brite" Phenotype in Differentiating 3T3-L1 Preadipocytes. PLoS One 9:e103093

4. Bastard JP, Jardel C, Bruckert E, Blondy P, Capeau J, Laville M, Vidal H \& Hainque B (2000) Elevated levels of interleukin 6 are reduced in serum and subcutaneous adipose tissue of obese women after weight loss. J Clin Endocrinol Metab 85:33383342

5. Bennetzen MF (2011) Investigations of the endocannabinoid system in adipose tissue: effects of obesity/ weight loss and treatment options. Dan Med Bull 58:B4269

6. Cavuoto P, McAinch AJ, Hatzinikolas G, Cameron-Smith D \& Wittert GA (2007) Effects of cannabinoid receptors on skeletal muscle oxidative pathways. Mol Cell Endocrinol 267:63-69

7. Cortez MY, Torgan CE, Brozinick JT, Jr. \& Ivy JL (1991) Insulin resistance of obese Zucker rats exercise trained at two different intensities. Am J Physiol 261:E613-619

8. Cota D, Marsicano G, Tschop M, Grubler Y, Flachskamm C, Schubert M, Auer D, Yassouridis A, Thone-Reineke C, Ortmann S, et al. (2003) The endogenous cannabinoid system affects energy balance via central orexigenic drive and peripheral lipogenesis. J Clin Invest 112:423-431

9. Crespillo A, Suarez J, Bermudez-Silva FJ, Rivera P, Vida M, Alonso M, Palomino A, Lucena MA, Serrano A, Perez-Martin M, et al. (2010) Expression of the cannabinoid system in muscle: effects of a high-fat diet and CB1 receptor blockade. Biochem J 433:175-185

10. DeFronzo RA \& Tripathy D (2009) Skeletal muscle insulin resistance is the primary defect in type 2 diabetes. Diabetes Care 32 Suppl 2:S157-163

11. Deveaux V, Cadoudal T, Ichigotani Y, Teixeira-Clerc F, Louvet A, Manin S, Nhieu JT, Belot MP, Zimmer A, Even P, et al. (2009) Cannabinoid CB2 receptor potentiates obesity-associated inflammation, insulin resistance and hepatic steatosis. PLoS One 4:e5844

12. Di Marzo V (2008) Endocannabinoids: synthesis and degradation. Rev Physiol Biochem Pharmacol 160:1-24

13. Di Marzo V, Cote M, Matias I, Lemieux I, Arsenault BJ, Cartier A, Piscitelli F, Petrosino S, Almeras N \& Despres JP (2009) Changes in plasma endocannabinoid levels in viscerally obese men following a 1 year lifestyle modification programme and waist circumference reduction: associations with changes in metabolic risk factors. Diabetologia 52:213-217

14. Di Marzo V, Goparaju SK, Wang L, Liu J, Batkai S, Jarai Z, Fezza F, Miura GI, Palmiter RD, Sugiura T, et al. (2001) Leptin-regulated endocannabinoids are involved in maintaining food intake. Nature 410:822-825

15. Eckardt K, Sell H, Taube A, Koenen M, Platzbecker B, Cramer A, Horrighs A, Lehtonen M, Tennagels N \& Eckel J (2009) Cannabinoid type 1 receptors in human skeletal muscle cells participate in the negative crosstalk between fat and muscle. Diabetologia 52:664-674

16. Etgen GJ, Jr., Jensen J, Wilson CM, Hunt DG, Cushman SW \& Ivy JL (1997) Exercise training reverses insulin resistance in muscle by enhanced recruitment of GLUT-4 to the cell surface. Am J Physiol 272:E864-869

17. Fellmann L, Nascimento AR, Tibirica E \& Bousquet P (2013) Murine models for pharmacological studies of the metabolic syndrome. Pharmacol Ther 137:331-340

18. Gaster M, Staehr P, Beck-Nielsen H, Schroder HD \& Handberg A (2001) GLUT4 is reduced in slow muscle fibers of type 2 diabetic patients: is insulin resistance in type 2 diabetes a slow, type 1 fiber disease? Diabetes 50:1324-1329

19. Heyman E, Gamelin FX, Aucouturier J \& Di Marzo V (2012) The role of the endocannabinoid system in skeletal muscle and metabolic adaptations to exercise: potential implications for the treatment of obesity. Obes Rev 13:1110-1124

20. Iannotti FA, Piscitelli F, Martella A, Mazzarella E, Allara M, Palmieri V, Parrella C, Capasso R \& Di Marzo V (2013) Analysis of the "endocannabinoidome" in peripheral tissues of obese Zucker rats. Prostaglandins Leukot Essent Fatty Acids 89:127-135

21. Iwasaki Y, Tamura Y, Inayoshi K, Narukawa M, Kobata K, Chiba H, Muraki E, Tsunoda N \& Watanabe T (2011) TRPV1 agonist monoacylglycerol increases UCP1 content in brown adipose tissue and suppresses accumulation of visceral fat in mice fed a high-fat and high-sucrose diet. Biosci Biotechnol Biochem 75:904-909

22. Lindborg KA, Jacob S \& Henriksen EJ (2011) Effects of Chronic Antagonism of Endocannabinoid-1 Receptors on Glucose Tolerance and Insulin Action in Skeletal Muscles of Lean and Obese Zucker Rats. Cardiorenal Med 1:31-44

23. Lindborg KA, Teachey MK, Jacob S \& Henriksen EJ (2010) Effects of in vitro antagonism of endocannabinoid-1 receptors on the glucose transport system in normal and insulin-resistant rat skeletal muscle. Diabetes Obes Metab 12:722-730

24. Lipina C, Stretton C, Hastings S, Hundal JS, Mackie K, Irving AJ \& Hundal HS (2010) Regulation of MAP kinase-directed mitogenic and protein kinase B-mediated signaling by cannabinoid receptor type 1 in skeletal muscle cells. Diabetes 59:375385

25. Liu J, Wang L, Harvey-White J, Huang BX, Kim HY, Luquet S, Palmiter RD, Krystal G, Rai R, Mahadevan A, et al. (2008) Multiple pathways involved in the biosynthesis of anandamide. Neuropharmacology 54:1-7

26. Liu YL, Connoley IP, Wilson CA \& Stock MJ (2005) Effects of the cannabinoid CB1 receptor antagonist SR141716 on oxygen consumption and soleus muscle glucose uptake in Lep(ob)/Lep(ob) mice. Int J Obes (Lond) 29:183-187

27. Massa F, Mancini G, Schmidt H, Steindel F, Mackie K, Angioni C, Oliet SH, Geisslinger G \& Lutz B (2010) Alterations in the hippocampal endocannabinoid system in diet-induced obese mice. J Neurosci 30:6273-6281 
28. Matias I, Gonthier MP, Orlando P, Martiadis V, De Petrocellis L, Cervino C, Petrosino S, Hoareau L, Festy F, Pasquali R, et al. (2006) Regulation, function, and dysregulation of endocannabinoids in models of adipose and beta-pancreatic cells and in obesity and hyperglycemia. J Clin Endocrinol Metab 91:3171-3180

29. Matias I, Petrosino S, Racioppi A, Capasso R, Izzo AA \& Di Marzo V (2008) Dysregulation of peripheral endocannabinoid levels in hyperglycemia and obesity: Effect of high fat diets. Mol Cell Endocrinol 286:S66-78

30. Murdolo G, Kempf K, Hammarstedt A, Herder C, Smith U \& Jansson PA (2007) Insulin differentially modulates the peripheral endocannabinoid system in human subcutaneous abdominal adipose tissue from lean and obese individuals. J Endocrinol Invest 30:RC17-21

31. Okumura N, Hashida-Okumura A, Kita K, Matsubae M, Matsubara T, Takao T \& Nagai K (2005) Proteomic analysis of slow- and fast-twitch skeletal muscles. Proteomics 5:2896-2906

32. Pagotto U, Marsicano G, Cota D, Lutz B \& Pasquali R (2006) The emerging role of the endocannabinoid system in endocrine regulation and energy balance. Endocr Rev 27:73-100

33. Pi-Sunyer FX, Aronne LJ, Heshmati HM, Devin J, Rosenstock J \& Group RI-NAS (2006) Effect of rimonabant, a cannabinoid-1 receptor blocker, on weight and cardiometabolic risk factors in overweight or obese patients: RIO-North America: a randomized controlled trial. JAMA 295:761-775

34. Polak J, Klimcakova E, Moro C, Viguerie N, Berlan M, Hejnova J, Richterova B, Kraus I, Langin D \& Stich V (2006) Effect of aerobic training on plasma levels and subcutaneous abdominal adipose tissue gene expression of adiponectin, leptin, interleukin 6, and tumor necrosis factor alpha in obese women. Metabolism 55:1375-1381

35. Puigserver P \& Spiegelman BM (2003) Peroxisome proliferator-activated receptor-gamma coactivator 1 alpha (PGC-1 alpha): transcriptional coactivator and metabolic regulator. Endocr Rev 24:78-90

36. Purves RD (1992) Optimum numerical integration methods for estimation of area-under-the-curve (AUC) and area-underthe-moment-curve (AUMC). J Pharmacokinet Biopharm 20:211-226

37. Silvestri C \& Di Marzo V (2013) The endocannabinoid system in energy homeostasis and the etiopathology of metabolic disorders. Cell Metab 17:475-490

38. Silvestri C, Ligresti A \& Di Marzo V (2011) Peripheral effects of endocannabinoid system in energy homeostasis : Adipose tissue, liver and skeletal muscle. Rev Endocr Metab Disord 12:153-162

39. Starowicz KM, Cristino L, Matias I, Capasso R, Racioppi A, Izzo AA \& Di Marzo V (2008) Endocannabinoid dysregulation in the pancreas and adipose tissue of mice fed with a high-fat diet. Obesity (Silver Spring) 16:553-565

40. Szallasi A, Cortright DN, Blum CA \& Eid SR (2007) The vanilloid receptor TRPV1: 10 years from channel cloning to antagonist proof-of-concept. Nat Rev Drug Discov 6:357-372

41. Tedesco L, Valerio A, Dossena M, Cardile A, Ragni M, Pagano C, Pagotto U, Carruba MO, Vettor R \& Nisoli E (2010) Cannabinoid receptor stimulation impairs mitochondrial biogenesis in mouse white adipose tissue, muscle, and liver: the role of eNOS, p38 MAPK, and AMPK pathways. Diabetes

42. Touati S, Meziri F, Devaux S, Berthelot A, Touyz RM \& Laurant P (2011) Exercise reverses metabolic syndrome in high-fat diet-induced obese rats. Med Sci Sports Exerc 43:398-407

43. Vettor R \& Pagano C (2009) The role of the endocannabinoid system in lipogenesis and fatty acid metabolism. Best Pract Res Clin Endocrinol Metab 23:51-63

44. Watkins BA \& Kim J (2014) The endocannabinoid system: directing eating behavior and macronutrient metabolism. Front Psychol 5:1506

45. Weisberg SP, McCann D, Desai M, Rosenbaum M, Leibel RL \& Ferrante AW, Jr. (2003) Obesity is associated with macrophage accumulation in adipose tissue. J Clin Invest 112:1796-1808

46. Wiklund PK, Pekkala S \& Cheng S (2013) Exercise, the endocannabinoid system and metabolic health. Journal of Sport and Health Science:60-61

47. Yan ZC, Liu DY, Zhang LL, Shen CY, Ma QL, Cao TB, Wang LJ, Nie H, Zidek W, Tepel M, et al. (2007) Exercise reduces adipose tissue via cannabinoid receptor type 1 which is regulated by peroxisome proliferator-activated receptor-delta. Biochem Biophys Res Commun 354:427-433

48. Zhang LL, Yan Liu D, Ma LQ, Luo ZD, Cao TB, Zhong J, Yan ZC, Wang LJ, Zhao ZG, Zhu SJ, et al. (2007) Activation of transient receptor potential vanilloid type-1 channel prevents adipogenesis and obesity. Circ Res 100:1063-1070

49. Zsombok A (2013) Vanilloid receptors--do they have a role in whole body metabolism? Evidence from TRPV1. J Diabetes Complications 27:287-292 


\section{12. Figures legends}

584 Fig 1. Expression level analysis of the genes related to endocannabinoid metabolism and function in control ( $\mathrm{Ctl}, \mathrm{n}=4)$, high fat diet 585 (HFD, $n=4)$, control with chronic exercise ( $\mathrm{Ctl}+$ training, $\mathrm{n}=4)$ and high fat diet with chronic exercise (HFD+training, $\mathrm{n}=4)$ groups. 586 mRNA expression levels of genes encoding for (a) endocannabinoid receptors ( $c n r 1$, cnr2, trpvl), (b) enzymes involved in AEA and 587 AEA congeners biosynthesis (abhd4, gde-1, nape-pld, ptpn22) and catabolism (faah), (c) enzymes involved in 2-AG biosynthesis

588 (dagl $\alpha$, dagl $\beta$ ) and catabolism (abhd6, abhd12, magl) were measured in subcutaneous adipose tissue. mRNA expression levels of 589 genes encoding for (d) endocannabinoid receptors, (e) enzymes involved in AEA and AEA congeners biosynthesis and catabolism, (f) 590 enzymes involved in 2-AG biosynthesis and catabolism were measured in visceral adipose tissue. The results obtained by qPCR are

591 reported using the $2^{\wedge}-\Delta \Delta$ ct formula using hprt as housekeeping gene. Each column is the mean \pm S.E. of at least four independent 592 determinations performed each in quadruplicate. * Significantly different from ctl group: $\mathrm{p}<0.05$.

\section{Fig 2.}

594 Expression level analysis of the genes related to endocannabinoid metabolism and function in control ( $\mathrm{Ctl}, \mathrm{n}=4)$, high fat diet (HFD, $595 \mathrm{n}=4)$, control with chronic exercise (Ctl+training, $\mathrm{n}=4$ ) and high fat diet with chronic exercise (HFD+training, $\mathrm{n}=4)$ groups. mRNA 596 expression levels of genes encoding for (a) endocannabinoid receptors (cnrl, cnr2, trpvl), (b) enzymes involved in AEA and AEA 597 congeners biosynthesis (abhd4, gde-1, nape-pld, ptpn22) and catabolism (faah), (c) enzymes involved in 2-AG biosynthesis (dagla, $598 \mathrm{dagl \beta}$ ) and catabolism (abhd6, abhd12, magl) were measured in soleus. mRNA expression levels of genes encoding for (d) 599 endocannabinoid receptors, (e) enzymes involved in AEA and AEA congeners biosynthesis and catabolism, (f) enzymes involved in 600 2-AG biosynthesis and catabolism were measured in extensor digitorum longus muscles. The results obtained by qPCR are reported 601 using the $2^{\wedge}-\Delta \Delta$ ct formula using hprt as housekeeping gene. Each column is the mean \pm S.E. of at least four independent 602 determinations performed each in quadruplicate. * Significantly different from ctl group: $\mathrm{p}<0.05$. 
Table 1. Fatty acid composition of the standard $(\mathrm{Ctl})$ and the high fat diet (HFD).

\begin{tabular}{|c|c|c|}
\hline & Ctl & HFD \\
\hline Total Fat (g/kg) & 27,50 & 395,47 \\
\hline Total Saturated Fat (g/kg) & 6,34 & 140,36 \\
\hline $\mathrm{C} 10: 0$ & - & 0,32 \\
\hline $\mathrm{C} 12: 0$ & 0,03 & 0,32 \\
\hline $\mathrm{C} 14: 0$ & 0,17 & 4,19 \\
\hline $\mathrm{C} 15: 0$ & 0,03 & 0,32 \\
\hline $\mathrm{C} 16: 0$ & 5,30 & 86,93 \\
\hline $\mathrm{C} 17: 0$ & 0,03 & 1,29 \\
\hline $\mathrm{C} 18: 0$ & 0,58 & 45,97 \\
\hline C20:0 & 0,10 & 0,94 \\
\hline $\mathrm{C} 22: 0$ & 0,06 & 0,07 \\
\hline $\mathrm{C} 24: 0$ & 0,06 & - \\
\hline Total Monounsaturated Fat (g/kg) & 5,61 & 171,18 \\
\hline C16:1 & 0,19 & 8,14 \\
\hline $\mathrm{C} 17: 1$ & 0,03 & 0,65 \\
\hline C18:1 & 5,09 & 158,96 \\
\hline C19:1 & - & 0,00 \\
\hline C20:1 & 0,30 & 2,80 \\
\hline $\mathrm{C} 22: 1$ & - & 0,65 \\
\hline Total Polyunsaturated Fat (g/kg) & $\mathbf{1 5 , 5 7}$ & 86,54 \\
\hline $\mathrm{C} 18: 2$ & 13,70 & 78,14 \\
\hline $\mathrm{C} 18: 3$ & 1,13 & 3,24 \\
\hline C18:4 & - & 2,58 \\
\hline $\mathrm{C} 20: 2$ & 0,03 & 1,29 \\
\hline $\mathrm{C} 20: 3$ & - & 0,65 \\
\hline C20:4 & 0,06 & - \\
\hline $\mathrm{C} 20: 5$ & 0,14 & - \\
\hline $\mathrm{C} 22: 1$ & 0,19 & - \\
\hline $\mathrm{C} 22: 4$ & - & 0,32 \\
\hline $\mathrm{C} 22: 5$ & 0,06 & 0,32 \\
\hline $\mathrm{C} 22: 6$ & 0,22 & - \\
\hline $\mathrm{C} 24: 1$ & 0,06 & - \\
\hline Total $\omega 3$ fatty acids $(\mathrm{g} / \mathrm{kg})$ & 1,57 & 3,91 \\
\hline Total $\omega 6$ fatty acids $(\mathrm{g} / \mathrm{kg})$ & 13,70 & 75,35 \\
\hline
\end{tabular}


Table 2: Primers sequences used in qPCR analysis

\begin{tabular}{|c|c|c|c|c|}
\hline Gene & $\begin{array}{c}\text { FORWARD Sequence } \\
\left(5^{\prime}->3^{\prime}\right)\end{array}$ & $\begin{array}{c}\text { REVERSE Sequence } \\
\left(5^{\prime}->3^{\prime}\right)\end{array}$ & $\begin{array}{l}\text { Enter Accession } \\
\text { Number }\end{array}$ & $\begin{array}{c}\text { Product } \\
\text { length } \\
\text { (bp) }\end{array}$ \\
\hline$a b h d_{12}$ & CAGGCGTGCGGTCGAAACCA & TCAAGCTGCAGTCGGCGTCC & NM_001024314.1 & 189 \\
\hline abhd $_{4}$ & TCTGGCGTCAAGCGGAGGGA & ACGCCACCCCCAAAGCCATG & NM_001108866.1 & 299 \\
\hline$a b h d_{6}$ & AGCGTCTGCTCCCATCCCCA & TGGCTTGCCAGTGGCGTGAA & NM_001007680.1 & 255 \\
\hline cnr-1 & CTGAGGGTTCCCTCCCGGCA & TGCTGGGACCAACGGGGAGT & NM_012784.4 & 285 \\
\hline cnr-2 & GCGGCTAGACGTGAGGTTGGC & TCCTTCAGGACCAAGAGTCTCAGCCT & NM_020543.4 & 335 \\
\hline dagla & GGCCGCACCTTCGTCAAGCT & ATCCAGCACCGCATTGCGCT & NM_001005886.1 & 380 \\
\hline $\operatorname{dagl\beta }$ & AGACCCGGGTGCAATGCTGC & GCCCTGGTGTGTGGGTCACG & NM_001107120.1 & 212 \\
\hline faah & GGCAGAGCCACAGGGGCTATCA & TGGGGCTACAGTGCACAGCG & NM_024132.3 & 349 \\
\hline gde-1 & GCAGCCCCTTCAACGCCTGT & GATGGCCGCCAGCGTGTTCT & NM_019580.4 & 172 \\
\hline magl & CGGAACAAGTCGGAGGTTGA & TGTCCTGACTCGGGGATGAT & NM_138502.2 & 220 \\
\hline nape-pld & AGGCTGGCCTACGAATCACGT & ATGGTACACGGGGGACGGCG & NM_199381.1 & 150 \\
\hline ptpn-22 & TGGTCGTGGGAGAGCCGCTT & GGGCCACTTTTTGCGCCTGC & NM_001106460.1 & 263 \\
\hline $\operatorname{trpv1}$ & AGACATCAGCGCCCGGGACT & CCAGCTTCAGCGTGGGGTGG & NM_031982.1 & 151 \\
\hline
\end{tabular}


Table 3. Effect of diet and / or exercise on body weight, food intake, maximal aerobic velocity (MAV), basal glucose and insulin levels, oral glucose tolerance test (OGTT) in control (Ctl, $n=7)$, high fat diet (HFD, n=7), control with chronic exercise $(\mathrm{Ctl}+$ training, $\mathrm{n}=7)$ and high fat diet with chronic exercise (HFD+training, $\mathrm{n}=7)$ groups.

\begin{tabular}{|c|c|c|c|c|c|}
\hline & Ctl & HFD & Ctl+training & HFD+training & Main effects by ANOVA \\
\hline $\begin{array}{l}\text { Weight (g) } \\
\text { Baseline }\end{array}$ & $95.4 \pm 5.4$ & $90.1 \pm 3.7$ & $93.6 \pm 6.0$ & $92.9 \pm 3.4$ & \multirow{2}{*}{$\begin{array}{l}\text { Time, } \mathrm{p}<0.0001 \\
\text { Diet, } \mathrm{p}<0.0001 \\
\text { Time } \mathrm{x} \text { Diet, } \mathrm{p}<0.0001\end{array}$} \\
\hline After diet period & $361.4 \pm 37.4$ & $437.3 \pm 34.7 \dagger$ & $366.7 \pm 22.8$ & $436.6 \pm 27.1 \dagger$ & \\
\hline $\begin{array}{l}\text { After diet and } \\
\text { exercise period }\end{array}$ & $428.3 \pm 46$ & $532.6 \pm 42.0 \dagger$ & $421.0 \pm 29.1$ & $494.6 \pm 24.4^{*}$ & $\begin{array}{l}\text { Time, } \mathrm{p}<0.0001 \\
\text { Diet, } \mathrm{p}<0.0001 \\
\text { Ex, NS } \\
\text { Diet } x \text { Ex, NS } \\
\text { Time x Diet, } \mathrm{p}<0.005 \\
\text { Time x Ex, } p<0.0001 \\
\text { Time x Ex x Diet, } \mathrm{p}<0.05\end{array}$ \\
\hline \multicolumn{6}{|c|}{ Mean caloric intake $\left(\right.$ Kcal.day $\left.^{-1}\right)$} \\
\hline $\begin{array}{l}\text { After diet and } \\
\text { exercise period }\end{array}$ & $68.3 \pm 11.9$ & $69.4 \pm 3.5$ & $\begin{array}{l}57.21 \pm 3.5 \\
70.3 \pm 3.9\end{array}$ & $\begin{array}{l}69.2 \pm 4.1 \\
75.6 \pm 2.1\end{array}$ & $\begin{array}{l}\text { Time, } \mathrm{p}<0.0001 \\
\text { Diet, } \mathrm{p}<0.0001 \\
\text { Ex, NS } \\
\text { Diet x Ex, NS } \\
\text { Time x Diet, } \mathrm{p}<0.005 \\
\text { Time x Ex, NS } \\
\text { Time x Ex x Diet, NS }\end{array}$ \\
\hline $\begin{array}{l}\text { MAV }\left(\mathbf{c m}_{\mathbf{s}}^{\mathbf{- 1}}\right) \\
\text { After diet period }\end{array}$ & & & $45.9 \pm 5.2$ & $41.6 \pm 3.9$ & \multirow{2}{*}{$\begin{array}{l}\text { Time, } \mathrm{p}<0.0001 \\
\text { Diet, } \mathrm{p}<0.05 \\
\text { Time } x \text { Diet, NS }\end{array}$} \\
\hline $\begin{array}{l}\text { After diet and } \\
\text { exercise period }\end{array}$ & & & $61.9 \pm 6.0$ & $55.8 \pm 5.0$ & \\
\hline $\begin{array}{l}\text { Plasma insulin } \\
(\text { ng.ml }\end{array}$ & $2.8 \pm 0.9$ & $2.9 \pm 0.5$ & $2.2 \pm 0.8$ & $2.5 \pm 0.3$ & $\begin{array}{l}\text { Diet, NS } \\
\text { Ex, NS } \\
\text { Diet x Ex, NS }\end{array}$ \\
\hline $\begin{array}{l}\text { Plasma glucose } \\
\left(\text { mg.dL }^{-1}\right)\end{array}$ & $83 \pm 3$ & $103 \pm 12^{\S}$ & $86 \pm 5$ & $92 \pm 5$ & $\begin{array}{l}\text { Diet, } \mathrm{p}<0.0001 \\
\text { Ex, NS } \\
\text { Diet x Ex, } p<0.05\end{array}$ \\
\hline OGTT (AUC) & $247.3 \pm 12.4$ & $306.7 \pm 20.4$ & $247.7 \pm 16.5$ & $286.1 \pm 9.8$ & $\begin{array}{l}\text { Diet, } \mathrm{p}<0.0001 \\
\text { Ex, NS } \\
\text { Diet x Ex, NS }\end{array}$ \\
\hline
\end{tabular}

Data are means $\pm \mathrm{SD}$;

The main effects from two- and three- way ANOVAs are as follows: Time, time effect; Diet, diet effect; Ex, exercise training effect; $x$, Interaction between variables, with repetitions on the Time effect

* Significantly different from $\mathrm{Ctl}+$ training, $\mathrm{p}<0.05 ; \uparrow$ Significantly different from $\mathrm{Ctl}$ and $\mathrm{Ctl}+$ training groups, $\mathrm{p}<0.05 ; \S$

Significantly different from all groups, $\mathrm{p}<0.05$

Table 4. Subcutaneous and visceral adipose tissues, and soleus and extensor digitorum longus (EDL) muscles concentrations of endocannabinoids and anandamide congeners in control (Ctl, $n=7$ ), high fat diet (HFD, $n=7)$, control with chronic exercise (Ctl+training, $n=7$ ) and high fat diet with chronic exercise (HFD+training, $n=7$ ) groups. 


\begin{tabular}{|c|c|c|c|c|c|}
\hline & Ctl & HFD & Ctl + training & HFD + training & $\begin{array}{c}\text { Main effects by } \\
\text { ANOVA }\end{array}$ \\
\hline \multicolumn{6}{|c|}{ Subcutaneous adipose tissue } \\
\hline AEA $\left(\right.$ pmol.mg $\left.g^{-1}\right)$ & $28.58 \pm 4.23$ & $33.47 \pm 3.22$ & $26.15 \pm 4.57$ & $31.27 \pm 4.44$ & $\begin{array}{l}\text { Diet, NS } \\
\text { Ex, NS } \\
\text { Diet x Ex, NS }\end{array}$ \\
\hline 2-AG (pmol.mg $\left.g^{-1}\right)$ & $0.60 \pm 0.15$ & $0.32 \pm 0.12$ & $0.52 \pm 0.19$ & $0.46 \pm 0.15$ & $\begin{array}{l}\text { Diet, } \mathrm{p}<0.02 \\
\text { Ex, NS } \\
\text { Diet x Ex, NS }\end{array}$ \\
\hline PEA (pmol.mg $\left.{ }^{-1}\right)$ & $0.43 \pm 0.09$ & $0.34 \pm 0.17$ & $0.38 \pm 0.09$ & $0.38 \pm 0.09$ & $\begin{array}{l}\text { Diet, NS } \\
\text { Ex, NS } \\
\text { Diet x Ex, NS }\end{array}$ \\
\hline$O E A\left(\right.$ pmol.mg $\left.g^{-1}\right)$ & $0.35 \pm 0.10$ & $0.35 \pm 0.07$ & $0.35 \pm 0.07$ & $0.34 \pm 0.02$ & $\begin{array}{l}\text { Diet, NS } \\
\text { Ex, NS } \\
\text { Diet x Ex, NS }\end{array}$ \\
\hline $\begin{array}{l}\text { Visceral adipose tissue } \\
A E A\left(\text { pmol. }^{-1} \mathrm{~g}^{-1}\right)\end{array}$ & $40.23 \pm 8.42$ & $35.40 \pm 17.37$ & $39.37 \pm 16,12$ & $28.55 \pm 6.79$ & $\begin{array}{l}\text { Diet, NS } \\
\text { Ex, NS } \\
\text { Diet x Ex, NS }\end{array}$ \\
\hline 2-AG (pmol.mg $\left.g^{-1}\right)$ & $0.28 \pm 0.15$ & $0.27 \pm 0.05$ & $0.33 \pm 0.13$ & $0.28 \pm 0.21$ & $\begin{array}{l}\text { Diet, NS } \\
\text { Ex, NS } \\
\text { Diet x Ex, NS }\end{array}$ \\
\hline PEA (pmol.mg $\left.{ }^{-1}\right)$ & $0.54 \pm 0.11$ & $0.80 \pm 0.38$ & $0.63 \pm 0.22$ & $0.50 \pm 0.11$ & $\begin{array}{l}\text { Diet, NS } \\
\text { Ex, NS } \\
\text { Diet x Ex, NS }\end{array}$ \\
\hline$O E A\left(\right.$ pmol.mg $\left.g^{-1}\right)$ & $0.39 \pm 0.08$ & $0.41 \pm 0.09$ & $0.42 \pm 0.10$ & $0.40 \pm 0.04$ & $\begin{array}{l}\text { Diet, NS } \\
\text { Ex, NS } \\
\text { Diet x Ex, NS }\end{array}$ \\
\hline $\begin{array}{l}\text { Soleus } \\
A E A\left(\text { pmol.mg } g^{-1}\right)\end{array}$ & $18.21 \pm 2.98$ & $38.60 \pm 10.84$ & $30.96 \pm 18.29$ & $35.71 \pm 15.28$ & $\begin{array}{l}\text { Diet, } \mathrm{p}<0.02 \\
\text { Ex, NS } \\
\text { Diet } x \text { Ex, NS }\end{array}$ \\
\hline 2-AG (pmol.mg $\left.g^{-1}\right)$ & $2.74 \pm 0.80$ & $1.74 \pm 0.40^{*}$ & $2.21 \pm 0.65$ & $2.28 \pm 0.60$ & $\begin{array}{l}\text { Diet, NS } \\
\text { Ex, NS } \\
\text { Diet x Ex, } p<0.04\end{array}$ \\
\hline PEA (pmol.mg $\left.g^{-1}\right)$ & $0.86 \pm 0.33$ & $0.70 \pm 0.23$ & $0.60 \pm 0.14$ & $0.61 \pm 0.15$ & $\begin{array}{l}\text { Diet, NS } \\
\text { Ex, NS } \\
\text { Diet x Ex, NS }\end{array}$ \\
\hline OEA (pmol.mg $\left.g^{-1}\right)$ & $0.21 \pm 0.02$ & $0.28 \pm 0.05$ & $0.22 \pm 0.06$ & $0.26 \pm 0.05$ & $\begin{array}{l}\text { Diet, } \mathrm{p}<0.006 \\
\text { Ex, NS } \\
\text { Diet x Ex, NS }\end{array}$ \\
\hline $\begin{array}{l}\text { EDL } \\
A E A\left(\text { pmol.mg } g^{-1}\right)\end{array}$ & $8.15 \pm 1.81$ & $18.45 \pm 4.35^{\S}$ & $6.73 \pm 2.05$ & $11.34 \pm 4.15$ & $\begin{array}{l}\text { Diet, } \mathrm{p}<0.00002 \\
\text { Ex, } \mathrm{p}<0.005 \\
\text { Diet } \mathrm{x} \text { Ex, } \mathrm{p}<0.05\end{array}$ \\
\hline 2-AG $\left(\right.$ pmol.mg $\left.g^{-1}\right)$ & $0.68 \pm 0.15$ & $0.85 \pm 0.21$ & $0.73 \pm 0.29$ & $0.91 \pm 0.16$ & $\begin{array}{l}\text { Diet, } \mathrm{p}<0.04 \\
\text { Ex, NS } \\
\text { Diet x Ex, NS }\end{array}$ \\
\hline PEA $\left(\right.$ pmol.mg $\left.{ }^{-1}\right)$ & $0.56 \pm 0.24$ & $0.76 \pm 0.42$ & $0.54 \pm 0.24$ & $0.44 \pm 0.18$ & $\begin{array}{l}\text { Diet, NS } \\
\text { Ex, NS } \\
\text { Diet x Ex, NS }\end{array}$ \\
\hline OEA (pmol.mg $\left.g^{-1}\right)$ & $0.24 \pm 0.10$ & $0.42 \pm 0.17$ & $0.27 \pm 0.14$ & $0.25 \pm 0.06$ & $\begin{array}{l}\text { Diet, NS } \\
\text { Ex, NS } \\
\text { Diet x Ex, NS }\end{array}$ \\
\hline
\end{tabular}

* Significantly different from Ctl group, $\mathrm{p}<0.05$; ${ }^{\S}$ Significantly different from all the groups, $\mathrm{p}<0.05$ 

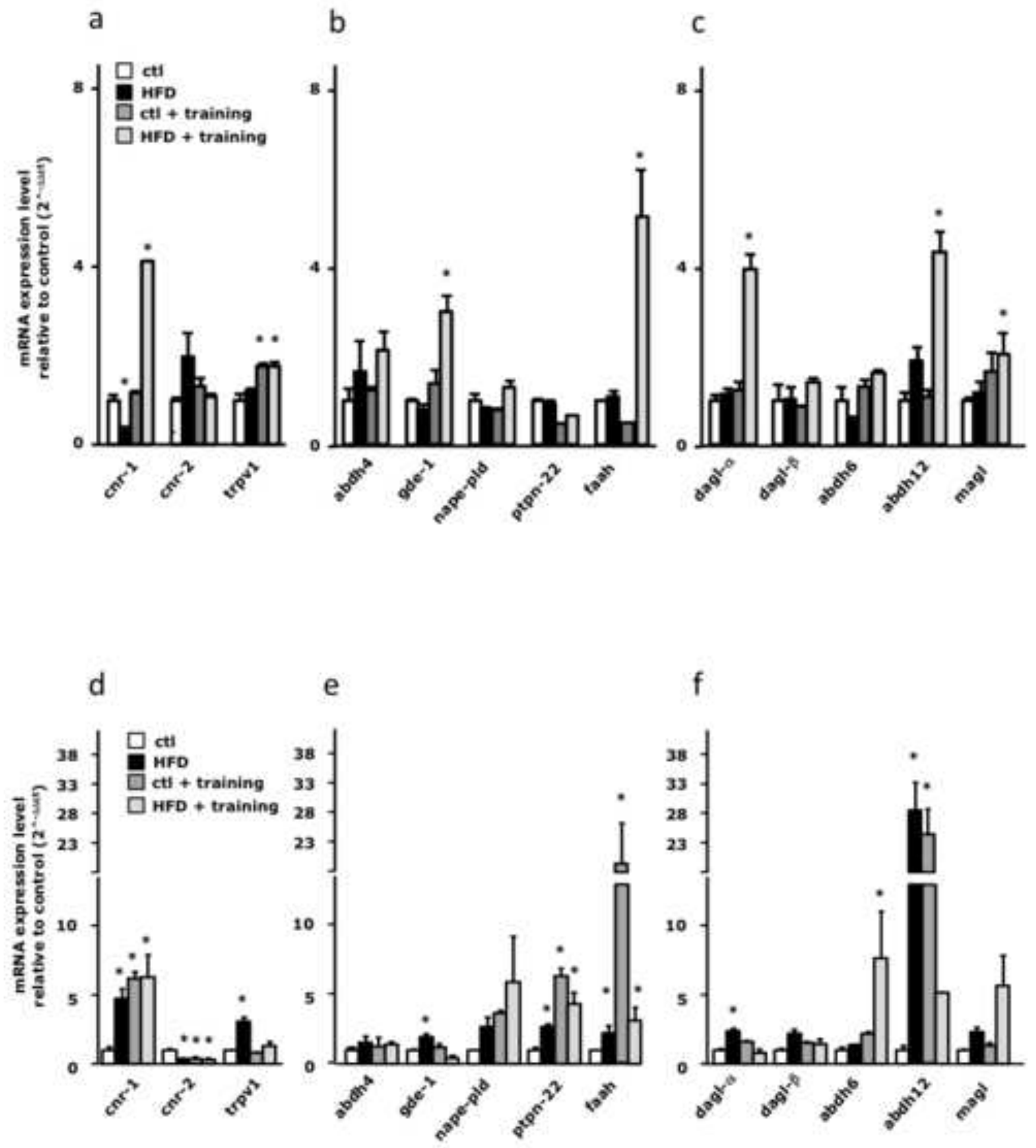

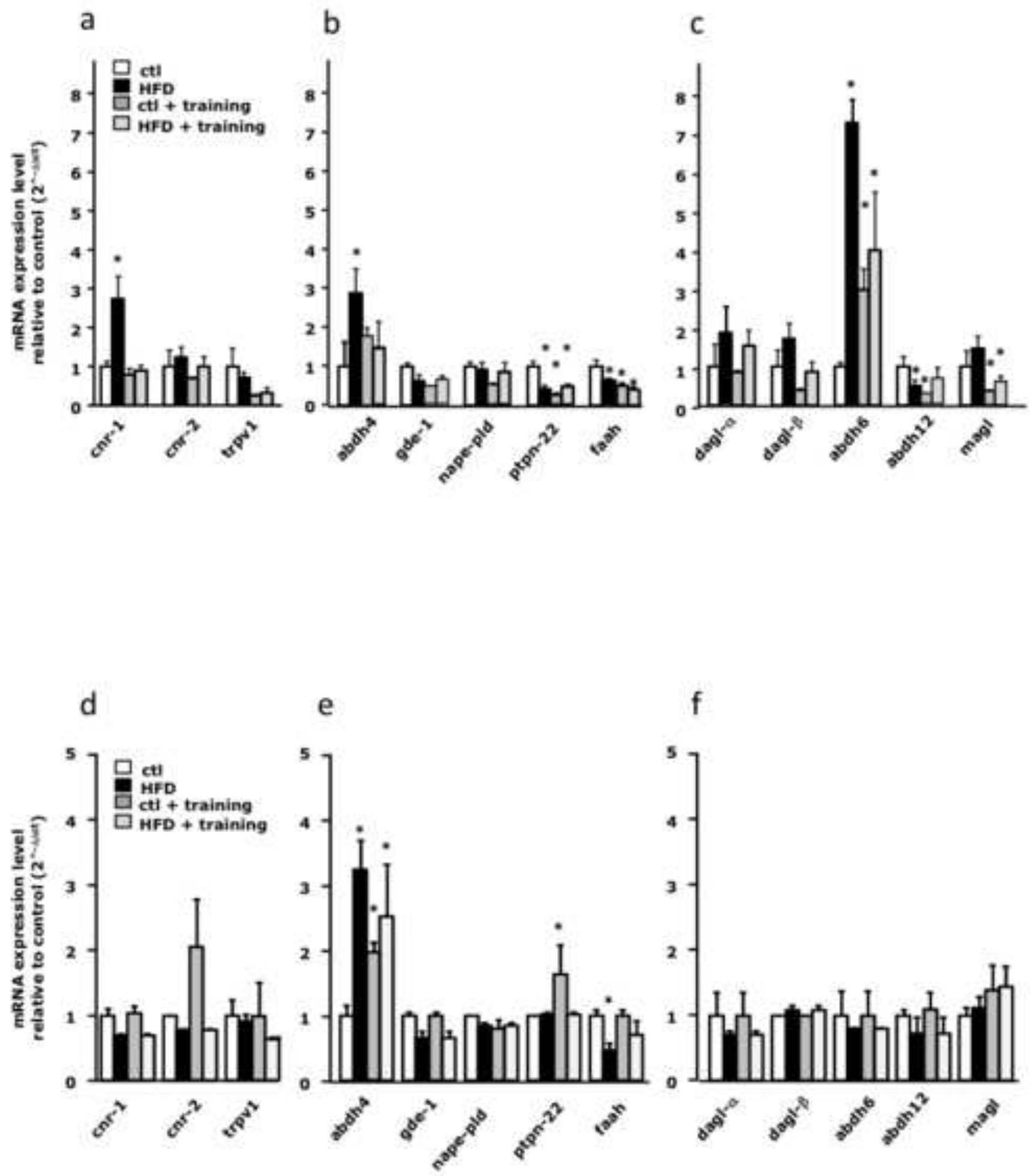